\title{
EVALUATION OF LOCAL TRAFFIC SAFETY PLANS
}

\author{
ULF RYDNINGEN $^{1,2} \&$ DANIEL SALBU ${ }^{1}$ \\ ${ }^{1}$ Department of Civil and Environmental Engineering, Oslo Metropolitan University, Norway \\ ${ }^{2}$ Department of Sociology, Political Science and Planning, \\ University of Troms $\varnothing$ - The Arctic University of Norway, Norway
}

\begin{abstract}
Plan evaluation has recently received considerable attention from planning scholars, while plan evaluation methods are not commonly used in practice. Evaluation tells decision-makers whether and how effectively their projects and policies have achieved their intended goals. In this study, the plan quality and plan content of 50 municipal road safety plans are analysed. The selected municipalities represent municipalities of various sizes in Norway. The purpose was to investigate which factors contribute to increase the quality of the plans, and which topics the plans mostly focus on. From our results we have arranged the municipalities into two main groups: first, we have looked at whether municipality sizes (small vs. larger) can explain any differences in plan quality; second, we have investigated whether there is a difference in plan content between municipalities that are involved in different types of local safety networking. The goal of a municipal traffic safety plan is to increase municipalities' efforts in traffic safety work, especially preventing road accidents among school children. One quality characteristic is the description and prioritization both of measures that the municipality itself has control over, and measures controlled by other cooperating public agencies and private organizations with interests in traffic safety controls, within the municipality's geographical delimitation. Our results demonstrate that for many plan documents, it is often difficult to reveal which actors have been involved in the plan-making process, and further which actors have responsibilities for the implementation. New expectations to plan content are mentioned, but are seldom discussed and usually do not lead to any new local policy or change measures. Our results will primarily inspire the municipalities to prepare better plans, but may also be a useful input to future revisions of national traffic safety plan guidelines.
\end{abstract}

Keywords: traffic safety, plan evaluation.

\section{INTRODUCTION}

Traffic accidents have long been an undesirable effect of today's transport intensive society. Worldwide, approximately 1.35 million people die each year as a result of road traffic accidents, and more than half of all road traffic deaths are among the most vulnerable road users: pedestrians, cyclists, and motorcyclists. Road traffic injuries are the leading cause of death for children and young adults aged 5-29 years.

Norway currently has 422 municipalities, and these have a responsibility to coordinate and plan the improvement of traffic safety within their geographical borders. From 2001, it has been a prerequisite for being able to apply for state funds for safer school roads, that the municipalities prepare action plans for road safety. Norwegian municipalities vary greatly in their population size, from Oslo (681,000 inhabitants) to the west coast island of Utsira (200 inhabitants). The traffic safety problems are therefore different, both in scope and character. A small Norwegian coastal municipality describes its understanding of local traffic safety as "Traffic safety is about people being able to move safely in their local environment, whether you are a pedestrian, a cyclist or a motorist - children, youth, or adults".

Since 1998, there has existed a national handbook for the preparation of municipal traffic safety plans (TS-plans), which is intended as a support for all types of municipalities. Recommendations are given on how to deal with municipal traffic safety plans, which topics should be investigated, ideas for measures and how basic data on traffic accidents can be 
obtained. In order to succeed in the work, the handbook recommends that the planning process is anchored at a high political level in the municipality, and in addition provides interagency participation and has a "local ownership" of the plan-making process.

The municipal traffic safety plan must focus on actionable measures through the fact that the inhabitants, especially children and young people (and the schools in the municipality), are involved in the traffic safety work. Further, the plan must give an overview of traffic hazard spots and stretches on all roads in the municipality, i.e. municipality roads, county roads, and national roads. The traffic safety plan must contain a prioritization of traffic safety measures, as a basis for applying for state-owned traffic safety funds.

Elaboration of a municipal sub-plan for traffic safety is not required by law. However, counties annually allocate funds for various traffic safety measures and impose the following requirements for the allocation of funds: a municipal traffic safety plan may not be more than four years old, meaning a plan revision should be made every four years. When auditing the municipal sub-plan for traffic safety, the plans should refer to the Norwegian Public Roads Administration Manual V722 "Guidelines for Municipal Traffic Safety Plans" [1] underlying the work. Municipalities that do not comply with these requirements will most likely only be able to apply for a grant for the measure "revision of municipal traffic safety plan", and not for financial support of physical measures.

\subsection{New national planning expectations to local plan content}

\subsubsection{Accreditations based on voluntary efforts for local safety}

"Trygg Trafikk" (TT) a Norwegian private organization aiming for road safety work, established in 1956, shall, according to its statutes, promote traffic education in kindergarten and schools, and provide information and knowledge about road safety in local communities. Similar road safety organizations are also established in the other Nordic countries (e.g. "Nationalföreningen för trafiksikerhetens främjande" in Sweden, "Sikker Trafik" in Denmark), but also in several other European countries.

The municipalities are important road safety actors. The local administrations are responsible for accident prevention and improving the inhabitants' health and quality of life. This is due to their various local responsibilities as owners of local roads, schools, and kindergartens, and as buyers of transport services. Therefore, according to laws and regulations, the municipalities have a duty to perform systematic accident prevention work in all its sectors. Being accredited by "Trygg Trafikk" as a "Traffic-safe Municipality" demands fulfilling a set of criteria to the local traffic safety plan, both to its content and to the planning participation process. Further, accreditation as a "Traffic-safe Municipality" puts demands on the municipality employees' traffic behavior, on the routines for buying transport, and on documentation on fulfillment of demands on implementation of knowledge and measures in schools, kindergartens, and other branches of the municipal administration. So far, 101 municipalities are accredited as "Traffic-Safe Municipalities" [2].

"Safe Communities" is the international model for local accident prevention, recognized by the World Health Organization (WHO). Accreditation as a "Safe Community" is used in more than thirty countries, and in Norway twenty municipalities are certified. Being a "Safe Community" demands that the local community works on increased safety within the educational sector, through physical planning joined with appropriate regulations and enforcement. "Safe Communities" is also a multi-sectoral approach [3]. 


\subsubsection{New planning values}

During the past ten years, new laws, regulations, and national planning expectations have appeared with increasing demands on the content of municipal plans. By the 2009 revision of Norway's Planning and Building Act (PBA), new planning values are expressed in the PBA law's objective paragraph. Stronger requirements have been set for local planning to integrate national, regional and local interests, for sustainable development and universal design, and for safeguarding children's interests in local planning.

In addition, over the recent years, the government has demanded a stronger focus on public health in local planning. Through the Public Health Act, the municipalities are required to improve the public health, contribute to injury prevention and protect the public against factors with negative impact on health. In practice, this is demanding the municipalities to work more systematically and inter-sectionally with traffic safety.

\subsection{Research questions}

Since the social planning perspective is strengthened and clarified through the new Planning and Building Act to be a relevant tool for solving tasks that go across different sectors, including in the work on traffic safety issues, we have chosen to look at the following issues:

1) How do the municipalities take into account the new expectations for plan content (public health and universal design policies, informative and behavioral measures) in the composition of local traffic safety plans?

2) How are these new expectations to plan content treated in the local traffic safety plan texts (mentioned, implemented as visions, strategies, or measures)?

3) What plan content should be strengthened so that municipal traffic safety plans better fulfill the increased societal demands on plan content?

4) Which factors distinguish the quality of the best traffic safety plans from the others (size of the municipalities, consultant reports)?

To our knowledge, the significance of Norwegian municipalities being accredited organizations in the field of local safety to the traffic safety plans' content, has not previously been studied. With these new expectations, traffic safety work is regarded as a cross-sectoral work involving all businesses in the municipality. The action plan provides an overview of measures for the various agencies. The measures are both organizational, traffic-related and straightforward to physical road measures, and include the areas public health, kindergartens, schools, culture (including non-governmental organizations), health centers, and the municipal engineering sector. The measures are rooted in the municipal agencies' own plans, e.g. traffic education plans for kindergarten and schools, technical operation and plans for road measures, and travel policy for the municipality's employees.

\section{PLAN EVALUATION METHODOLOGY}

\subsection{Data capture and sample selection}

In 2019, Norway consists of 422 municipalities, but an ongoing local administration reform will result in a reduction to 356 municipalities from year 2020. The idea is that larger and stronger municipalities will provide better welfare services, a more sustainable social development, and stronger local governments.

We have randomly selected 50 municipalities for the evaluation of municipal traffic plans (Fig. 1). The population composition of the selected municipalities is different from the 
recent 422 communes, but will be probably be more in line with the new 356 municipalities (Table 1).

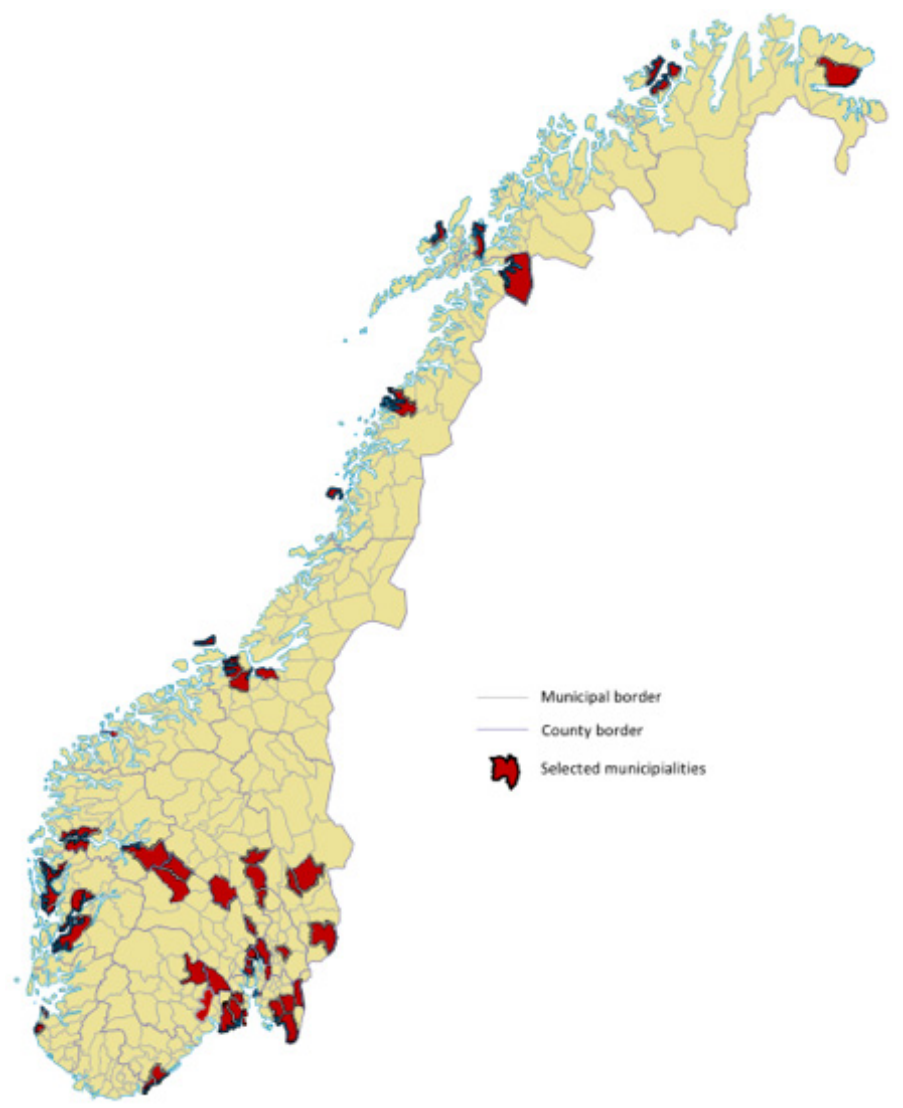

Figure 1: Selected municipalities.

Table 1: Population sizes of sample municipalities versus total in Norway.

\begin{tabular}{|l|c|c|}
\hline Population size & $\begin{array}{c}\text { Sample (\%) } \\
(n=50)\end{array}$ & $\begin{array}{c}\text { All municipalities (\%) } \\
(n=422)\end{array}$ \\
\hline$\leq 1,000$ & 2.0 & 7.1 \\
\hline $1,001-10,000$ & 32.0 & 66.1 \\
\hline $10,001-50,000$ & 50.0 & 23.0 \\
\hline $50,001-200,000$ & 14.0 & 3.3 \\
\hline$>200,000$ & 2.0 & 0.5 \\
\hline
\end{tabular}

The analysis gives results from a varied sample of municipalities, and provides some findings that reveal weaknesses and strengths that are not necessarily representative of the entire population, but which are interesting issues that should be addressed so that we can achieve even better road safety plans. 


\subsection{Plan evaluation}

Evaluation plans are the subject of an extensive amount of literature. Some previous studies have focused on methods and criteria for plan evaluation [4]-[8], while others have conducted a theme-based plan evaluation, which addresses, for example, climate change [9][11] or public health [12].

There are three possible approaches to plan evaluation, the first is normative, the second is by conformance and the third is by performance [13]. The normative approach hardly qualifies as a formal evaluation approach: it is more of a historic analysis and review that evaluates the quality of the planning and decision-making process in terms of the planners' contemporary norms and available methods and information, and judges the resulting plan by its experienced impacts on the affected society [14]. The conformance approach judges the success or failure of planning efforts by either of two standards. One is the degree to which outcomes "on the ground" fit the plan or conform to the planning policy prescriptions. The other is whether the tools deployed to implement a policy or plan in fact work to promote its espoused objectives [14]. Performance-based evaluation follows from defining a plan or policy as a framework for future decisions. Performance means a plan's or policy's usefulness and effectiveness in this role: whether the subject plan or policy was consulted for subsequent decisions and how it was followed in implementing related plans, programmes and projects [14].

In framing an evaluation of planning, the choice between the conformance-based and the performance-based ways of evaluating plans depends on the answer to the question: What is the function of the municipal traffic safety plans? If the plan is meant to be implemented and thus change the built and experienced environment, its evaluation demands applying the conformance approach. On the other hand, if a plan's main purpose is to frame lower order plans and subsequent implementation decisions, it should be evaluated using the performance approach. The role of the Norwegian Handbook for Traffic Safety Plans is as follows:

The goal of a municipal traffic safety plan is to increase the municipality's efforts in traffic safety work. Since year 2001, such a plan will be a prerequisite for obtaining state financial support for planning and implementing measures for securing children's school paths on county roads and municipal roads [1].

Here it is quite clear that the role of the local Norwegian traffic safety plans is to achieve both a vertical and horizontal coordination of policies and responsibilities for the implementation of local traffic safety work. The implementation requires that the plans' measures are implemented in the various actors' (local development) plans and budgets. This means that municipal traffic safety plans must be perceived as a framework for future decisions, i.e. that a conformance-based evaluation is chosen.

\subsection{Content analysis}

In a qualitative text analysis, a content analysis is used, where the presence of certain predetermined phenomena in texts is made visible. This method helps to see the text based on a specific purpose, for example from a gender perspective. The perspective will help to describe the content of the text in a systematic manner. The purpose of such an analysis is to see the underlying significance of the content, such as which target group the text is aimed at or which groups are excluded. Such analyses are useful for general societal values [15]. 
In order to carry out this analysis, an analytical instrument - a checklist - was constructed. The checklist helps to delimit the collected material. The boundaries must be determined in advance and noted in the checklist [15]. Predicted keywords or expressions that help to find patterns in the text were then used. It is important that each keyword and expression has a definition for getting a distinct meaning from the analysis, which should give an increased understanding of the results of the analysis. Since the goal of the content analysis is to find patterns in the text, it is important that the checklist and keywords are used consistently. When analysing several texts, these were analysed in a similar way to give a fair result, therefore the checklist as well as the keywords are an aid that contributes to a fair assessment. To ensure the analysis is fair, the results have been checked several times (double-coding).

In this study, a content analysis with an abductive approach has been performed to analyse the local traffic safety plans. Abduction means that individual cases are interpreted on the basis of a predetermined underlying pattern and takes into account empirical observations and impressions. The interpretation should then be substantiated by new observations. During the course of the process, the empirical application areas are partially developed, in order to refine and adjust the underlying pattern. In this case, the underlying pattern consists of a checklist and keywords, both of which were developed during the analysis process. The empirical environment contributes to new understanding and continued development for the analysis. In this analysis model, the focus on the underlying pattern is an advantage - it contributes to flexibility, since the understanding is also included in the analysis. Abduction is based on empirical facts and theoretical beliefs [16].

The basis of the checklist has been taken from both deep theoretical knowledge of traffic safety and plan evaluation, as well as long experience as an traffic safety officer. The selection of issues has been taken from the NPRA Handbook on Traffic Safety Plans, the "Trygg Trafikk" guidelines, by reading through local traffic safety plans and by inspiration from previous literature on plan evaluation. The next step in the analysis was to examine the traffic safety plans. During the review, new questions arose, which meant that the checklist was further developed and the traffic safety plans were reviewed again. This meant that the checklist developed progressively during the analysis of the plans. The questions in the checklist were changed, adapted and designed during the analysis. This has contributed to the traffic safety plans being double-coded, discussed and analysed several times. The double coding meant that the traffic safety plans were analysed by both evaluators several times and then the analyses were compared with each other, which resulted in a joint compilation. The final review of the traffic safety plans resulted in the purpose being met, using a content analysis to find out whether the new national planning perspectives was integrated into the traffic safety plans. The structure of the checklist was based on different approaches: existing questions from reports, questions based on the theory, and abduction between the checklist and the traffic safety plans.

\subsubsection{Analytical tool used}

The data gathered from quantitative content analysis of traffic safety plans was processed using the IBM SPSS statistical software, version 24. A frequent used statistical evaluation technique here is chi-square testing of crosstabs. Cronbachs alpha is calculated for the two coders, giving a match on $87 \%$. For text analysis, in order to reveal the plan policies, every plan document was imported directly into NVivo, analysing the plan policy. 


\section{PLAN CONTENT AND QUALITY FINDINGS}

\subsection{Plan preparation and plan presentation}

\subsubsection{Plan presentation quality}

We first mapped out whether all 422 municipalities had prepared and adopted local traffic safety plans. Subsequently, the plans' validity periods were registered, as well as information on the use of consultants for the plan preparation. Through web-based information, we revealed that for 110 municipalities $(26 \%)$ we have found no information whether they have prepared any traffic safety (TS) plan or not.

For evaluating plan presentation status and plan validity we coded eleven themes, which in total could achieve 22 points. The results varied from nine to twenty points, with an average on 12.9 points. Assessment of the quality of the plan presentation may be regarded as an indication of how easy it is as a reader to familiarize yourself with the idea of the plan, and understand how the plan's content is structured and selected. As a long-time reader of scientific literature and student reports, one experiences that some written work is easier and more pleasurable to read than others. These experiences may be valid for other readers too. A plan's quality of presentation may be decisive for whether, or how much of, a report a local politician or others use a report. We therefore coded the presence and quality of the traffic safety plans table of contents, a report summary, an assessment of the quality of map design, and size, readability of and explanation to tables and figures. Further, we assessed a general impression of the readability of the plan document, whether the front page included period statements - date of adoption and expiration date - and the date of adoption of the plan in the municipal council. All these elements were coded $0-2$.

The presence and quality of the list of contents scored high among the plans in our sample (mean 1.7), nine plans (18\%) were either lacking a table of contents, or had no or faulty page numbering compared to the table of contents. A traffic safety plan typically presents some information about accident types and accident locations. It is of utter importance for the reader that maps have large enough symbols and clear legends, and our evaluation revealed that the sizes and presentations of maps and figures were not satisfactory, with a mean of 1.0 points. Also, the quality of the tables were generally low, with a mean score of 1.1 points. Further, the plan summary achieved 1.5 points. Generally, there is also a potential of improving the front-page information about the plan's duration period, which achieved 1.4 points for date of adoption and 1.1 points for whether the plan expiration date was included or not. We also appreciated whether information was given about the report's author(s) and members of the project group. Here it is of interest to give information about who participated (including title and workplace). Quite often such information was lacking, so the plans averaged a score of 1.3 points. All of these themes are easy to improve and require no analytical skills to complete. One last theme was the presence of a reference list, either directly at the end of the report, or indirectly as mentioned in the text. 41 of the 50 traffic safety plans studied were lacking information on which knowledge and factinformation their arguments were based on.

\subsubsection{Use of consultants}

Loh and Norton [17] found that consultant involvement - along with professional planning staff capacity and officials' commitment to planning - does appear to have a significant effect on the policy focus of plans. $49(16 \%)$ of the municipalities in Norway, for which we have data, had hired a consultant company to prepare traffic safety plans. Among our sample of the selected 50 municipalities, eight (16\%) have also used a consultant company for plan 
preparation. One might think that it is the smallest municipalities (in population) which tends to hire consultant companies to prepare a TS plan. This would be because small municipalities have a limited number of planning officers employed, and often they lack an updated expertise of traffic safety among them. However, from our data we find no indication that our hypothesis of the small municipalities' needs to hire a consultant company due to lack of capacity or competence. We see that the $p$-value is 0.151 , which indicates that there is no significant difference between large and small municipalities in consultant use.

All in all, the plan document texts indicate that even the smallest municipalities seem to have a good understanding of the overall and local traffic safety issues. This may be from work experience and knowledge transfer, mainly from the content and plan examples in the national guidelines for traffic safety plan preparation.

\subsubsection{Participation process}

For evaluating the information about the planning processes, we investigated whether the composition of the plan work-groups, and the involvement of municipal agencies or other government agencies (local, regional, state), was described. It is also of interest to reveal the involvement of local NGOs in the plan-making process. Information about the working groups, but also on the participation process and how the planning process was anchored politically and administratively, were to a large degree lacking. There are big differences between the municipalities regarding which actors are asked to participate in the plan-making process and as consultation bodies. Methods of input to the plan also vary. While some municipalities ask the schools to identify traffic safety problems and make suggestions to relevant measures, other municipalities also consult transport companies, the municipal council for the disabled, the local police and the public roads administration. One middlesized municipality in southern Norway mentions:

\section{The traffic safety plan is based on information from a school survey completed at all primary schools, from youth workshops, and all inquiries to the planning department regarding traffic safety in recent years.}

Only every fourth TS-plan is describing whether and how the local politicians have participated in the planning process, this is in accordance with research on participation in plan-making of local traffic safety plans in Denmark [18]: "The politicians have been confined to a very limited extent - including in the goal setting discussions. This may mean that the political ownership of planning is weakening". Three TS-plans mention "the challenge for the municipal traffic safety work is to put the issue on the political agenda", so for some municipalities it may seem difficult to make such a thematic plan that is interesting enough politically. We believe this can be changed, both by updating the plan guidelines for TS-plans, by getting a more orderly involvement process, and anchoring in the political environment and by regarding traffic safety in relation to other sectors and political fields. This, however, places demands on changed competence, and interests to cooperate with others, among the plan authors. The TS-plans today are very much aimed at fulfilling the current norms from the Norwegian Public Roads Administration, which are very reductive with a road and footpath construction focus.

\subsubsection{Planning period and plan validity}

Median plan date of adoption was year 2015. Almost one-third of the adopted municipal road safety plans are older than 5 years (5-17), and one-third is from year 2016 or newer. The average (and median) expiration date was year 2019, meaning $50 \%$ of the plans will not be 
valid after year 2019. Release year indirectly says something about plan content. If the TS plans are older than 2008, then plans have not been updated with respect to the current overall policies (new planning and building act, etc.), and the TS-plans therefore lead to a partially outdated traffic safety policy.

\subsubsection{The scope of the TS plans}

The number of pages that the TS plan contains also varies between the municipalities. The arithmetic mean is 30 pages, standard deviation is 19.5 . The median is 26 pages, and by creating two groups, one consisting of the municipalities with plan documents less than 26 pages, the other larger than 26 pages, we find there is a significant difference between the $50 \%$ smallest and the $50 \%$ largest municipalities in the number of plan document pages $(p=0.027)$. The municipalities belonging to the group of fewest inhabitants also writes TS plans that have fewer pages. Most often it turns out that plans that are on few pages, all have prioritized to include action programs with prioritization and cost distribution of traffic safety measures. What is then lacking is a description of the planning process, plan strategies and overall policies and how these have influenced the plan-making.

\subsubsection{Plan legal status}

A municipal traffic safety plan may be adopted either as a sub-plan to the local master plan, or as a thematic subject-based plan. It is the municipality itself that will decide the plan status, but the national traffic safety guidelines suggest that a local traffic safety plan should be enacted as a municipal sub-plan. A sub-plan has to be made by the municipality itself, and cannot be produced by a consultant company. Legally this plan status then gives the same bindings as the municipal master plan, but compared to the master plan, a sub-plan is more detailed for a limited area or theme. An adopted municipal sub-plan is legally binding with effect for all and cannot be appealed. Contextually, whether a TS plan is adopted as a subplan or a thematic subject-based plan, they shall specify goals and strategies based on the long-term goals stated in the municipal plan. Such plans should have an action section that is rolled annually. They will describe the challenges in the field in question, set goals and define strategies to achieve the goals, as well as suggestions for measures to achieve the desired goals. The plans often tell how the municipality agencies and cooperating external actors should act and prioritize, based on an agreement in the plan-making. The financial priority is taken in the budget and the financial plan.

Looking at all municipal traffic safety plans in Norway, $25 \%$ of these are approved as municipal sub-plans, and for our sample of 50 plans $20 \%$ are sub-plans. The majority of municipal traffic safety plans are thus thematic subject-based plans, allowing to be prepared by consultants.

\subsubsection{Ex-post facto evaluations}

The ex post facto evaluations of individual plans and planning systems, which is widely accepted as an important means to improvement of the planning task, is a difficult and poorly managed task [...] to start with, it is not often easy to identify what is being evaluated. Policy, strategy and individual measures may be covert, implied or specific and there is the problem of null policy. [...] Moreover, if particular objectives are the subject of overlapping measures implemented by several agencies, it may be difficult to isolate the set of policies concerned with a given problem. For that matter, even within a single planning document, a single objective may be addressed by several policies [19], [20]. 
Nevertheless, one of our findings shows that a major shortcoming in most plans is to account for the status for the implementation of the previous plan. What was achieved by the policies and measures identified by the previous plan? Why were not all measures and strategies implemented and are these policies still known and relevant? This is something that is generally lacking, and in particular, consultant reports seem to be decoupled from such a starting point.

\subsection{Plan policy focus}

\subsubsection{Visions, strategies and goals for local traffic safety}

Often, local plans refer to overall policies such as the national transport plan or county plans, without describing how such overall policies are implemented at the local level into the traffic safety plan, or in other strategic municipal plans. Even though a majority of the municipalities have developed criteria for plan implementation, there seems to be a missing link between the recent national plan expectations and local plan implementation. Looking on the plan texts, the argumentations seem to be lacking some reflective thoughts on the new national policies. We might interpret this to mirror the competence of the authors of the reports, who to a large extent still seem to be led by highway and traffic engineers.

Most of the municipalities studied have designed visions and objectives for traffic safety work. Visions and goals are based on Vision Zero, which originated in Scandinavia. This applies in particular to consultant written reports. But there are few local, distinctive visions, objectives, and measures based on Vision Zero.

\subsubsection{Purpose of the plans}

A municipal council enacted road safety plan provides the opportunity to apply for support for planning and building of physical measures on public roads, and almost all municipalities highlight this as an important purpose of the plan, but we also find examples of other good, well-formulated plan intentions:

The traffic safety plan for 2014-2017 is about fulfilling the goal of reducing traffic accident numbers in our municipality. Furthermore, the plan shall assist in the municipality's overall traffic safety efforts guiding the planning and investment responsibilities for measures, when implemented and at what cost. It often turns out that within a municipality information is often lacking about tasks within each municipal agency.

\subsubsection{Description of the main road safety issues}

Only 20 of the 50 municipalities have in their TS-plans explained what the essential main challenges for traffic safety in the local community are. It seems quite remarkable that the municipalities do not describe the main problems they want to solve by implementing the plan. A small and rural community in Northern Norway describes its main challenges as follows:

The police's experience with the traffic in our village indicates that in many cases there is an indifference to traffic rules. Roadside controls from the traffic police show cases of mobile phone use, lack of use of seat belts and other unfortunate traffic behavior. The number of cases of driving influenced by alcohol varies and arrests are largely dependent on tips from the citizens, which is due to little staffing at the local police station. The police, however, 
have experienced an increase in general traffic issues lately. The traffic has slowed down in Main Street and increased correspondingly in Town Hall Street after speed bumps were installed. There have been reactions from the residents because of this increased traffic. The people involved in traffic accidents are often from the local community and thus know both the road standard and the traffic problems in our village. In order to avoid traffic problems, and to get a clearer traffic picture, the Main Street should be considered transformed to a cul-de-sac.

This statement illustrates the importance of collaborating with and obtaining statements from important traffic safety actors in the planning process. We also investigated whether the TS plans expressed something about what is perceived as the main problems for children's traffic safety in the local community. One example found was the following statement:

One important priority area for the coming years is to prioritize safe and attractive school roads for children and youngsters. Results from gathered information about informal pathways that children use, and incoming presentations presented in this plan show that there are more stretches, points and areas that should receive improved safety, if as many children and youngsters as possible should be able to travel safely to and from the school. Lack of safety in the local community or along the school road is closely linked to public health. The access must be ensured through safe walking and cycling routes. To facilitate health-promoting transport solutions such as pedestrian and bicycle paths, to offer an effective public transport, and to increase the level of competence on traffic safety issues for everyone, is an example of good public health measures.

Only seven out of the $50 \mathrm{TS}$ plans have mentioned anything about what is regarded as the main traffic safety problems for children and youths.

\subsection{Land use planning and traffic mode choice}

Traffic volume is approximately proportional to the number of accidents. How the local communities are planned and developed is therefore an important prerequisite for the local traffic safety. For example, scattered rural development often means long travel distances and few opportunities for traveling with other means of transport than cars, and thus more vehicle kilometers per capita than in denser urbanization [21]. Only $10 \%$ of the municipal TS-plans are reflecting on these issues, one example being:

The location of dwellings, schools, workplaces and leisure facilities will affect traffic safety. Uncritical placement of new housing estate far from the existing may provide costly demands for walking and cycling paths or other costly safety measures later.

Whether such good intentions are also laid down as new planning conditions for local detailed plans, has not been investigated here. 


\subsection{Traffic safety in a wider context}

\subsubsection{Universal design and public health}

Most municipalities have in their action plan described an intention to carry out information and influence measures in schools, kindergartens and among their own employees. A minority of the municipalities have also described that there is a need for special facilitation for people with reduced mobility.

For mobility and vision impaired people to be able to travel safely in road traffic, it is particularly important with well-marked crossing points. It is also important to have consistent and coherent signals and tactile elements on the ground. There may be situations where universal design and traffic safety come into conflict, and one must then look at these in relation to each other. Measures to improve traffic safety must be considered in relation to universal design and vice versa. Universal design should not be at the expense of safety, rather be used as a premise in traffic safety.

Only in a very few TS-plans is it suggested as a measure to undertake an audit for pedestrians with impairments. This in spite of the fact that universal design is required to be taken into account in all planning, according to the latest revision of the Planning and Building Act (2009). The lack of such policies might be related to inadequate competence in thinking strategically about universal design, but also to the fact that policies for universal design are found in other municipal thematic plans. Public health is often mentioned, especially in the latest TS plans. But as for universal design, we see that public health becomes a term that is referred to yet rarely leads to new actions, when we study the contents of the action programmes.

\subsubsection{Municipality Transport Policy}

The municipalities are large local employers, consumers, and buyers of transport services. Many of the employees travel during working hours. So, which requirements or expectations does the municipalities place on the safety of these trips? Examples may be the choice of means of transport, the focus on always using seat belts, keeping the speed limit and not driving under influence of alcohol (even though this is already legally required), collision safety requirements for cars, or acceptance to postpone travel if weather and driving conditions so dictate. By setting requirements for approved and safe equipment when purchasing transport services, the municipalities can contribute to increased traffic safety. $32 \%$ of the municipalities studied, have in their traffic safety plan set requirements for safety equipment on buses that carry schoolchildren on study-tours, and $22 \%$ of the municipalities have prepared traffic safety policies for employee travel services. These are new conditions that are specifically mentioned in the new recommendations from "Trygg Trafikk" to be accredited as a "Traffic-safe Municipality".

\section{CONCLUDING REMARKS}

An analysis of 50 municipal traffic safety plans shows that the vast majority of the plans apparently satisfy a relatively good content, in line with recommendations in the state guidelines for municipal traffic safety plans. A plan prepared according to the Norwegian Public Roads Administration's guidelines for traffic safety plans does not necessarily mean that the planning document is a very interesting political document, or that the level of reflection is very high. The plan authors, whether they are municipal employees or 
consultants, seem to have a good overview of the traffic safety issues, but greater problems with seeing traffic safety in a larger context across the municipal sector. Traffic safety nowadays is seen to a greater extent as a topic that is covered by the entire municipality's activities, and not just as previously as physical measures to be implemented on the roads. The answer to how the municipalities take care of the new expectations for planning is twofold. The 101 municipalities and others who work to qualify calling themselves "Trafficsafe Municipalities" seem to have attained a changed focus on the purpose of traffic safety information, training and collaboration across the municipality's sectors in order to achieve overall better local traffic safety. However, an overall objective of changing the means of transport as an effective transport safety policy is most often lacking. Demanding traffic safety as a prerequisite for location principles, has shown to be poorly, if at all, described. This may be related to the plan author's expertise, who more often than not is from the highway engineering or the road maintenance field. This may be improved by closer cooperation with municipal master planning officers.

What distinguishes the best plans from the worst plans with regards to plan quality, is the quality of maps, figures, photos and tables as well as a good overall impression of the plans' readability. The best plans often impress us with having some qualities that are not compulsory in the plan guide, such as references. This testifies to a reflected attitude and serious intentions in the planning process. But clearly, the plan policy content is the most interesting part, and we find many good intentions are mentioned, yet few are discussed and often do not result in any new policies. A small minority of the plans studied are of a very high quality, showing a higher level of reflection, more innovative strategies and taking greater overall social responsibility, as well as conducting better vertical and horizontal integration. Our analyses reveal that more collaboration and better political grounding and knowledge of what makes a plan politically interesting is needed. The current guidelines for TS plan preparation should focus more on the planning process and be updated with the new national expectations of TS plans. For traffic safety there is, as far as we know, no organized network for exchange of experience, such as there is for instance for universal design and public health. We recommend establishing a better organized exchange of experiences so that the municipalities can learn from each other. This, besides providing better, more updated TS plan guidelines, ought to be a national (funded) responsibility.

REFERENCES
[1] Vegdirektoratet, Kommunale trafikksikkerhetsplaner: Veiledning (Håndbok V722), Statens vegvesen, 2014.

[2] Trygg Trafikk, Trafikksikker kommune, Godkjente kommuner. www.tryggtrafikk.no/ trafikksikker-kommune/godkjente-kommuner/. Accessed on: 15 Apr. 2019.

[3] ISCCC, International Safe Communities. https://isccc.global/. Accessed on: 16 Apr. 2019.

[4] Talen, E., After the plans: Methods to evaluate the implementation success of plans. Journal of Planning Education and Research, 16(2), pp. 79-91, 1996.

[5] Laurian, L. et al., Evaluating plan implementation: A conformance-based methodology. Journal of the American Planning Association, 70(4), pp. 471-480, 2004.

[6] Balsas, C., What about plan evaluation? Integrating evaluation in urban planning studio's pedagogy. Planning Practice and Research, 27(4), pp. 475-494, 2012.

[7] Laurian, L. et al., What drives plan implementation? Plans, planning agencies and developers. Journal of Environmental Planning and Management, 47(4), pp. 555-577, 2004. 
[8] Berke, P. et al., What makes plan implementation successful? An evaluation of local plans and implementation practices in New Zealand. Environment and Planning B: Planning and Design, 33(4), pp. 581-600, 2006.

[9] Berke, P.R. \& Conroy, M.M., Are we planning for sustainable development? Journal of the American Planning Association, 66(1), pp. 21-33, 2000.

[10] McNamara, K.E. \& Buggy, L., Community-based climate change adaptation: A review of academic literature. Local Environment, 22(4), pp. 443-460, 2017.

[11] Allman, L., Fleming, P. \& Wallace, A., The progress of English and Welsh local authorities in addressing climate change. Local Environment, 9(3), pp. 271-283, 2004.

[12] Hofstad, H., Healthy urban planning: Ambitions, practices and prospects in a Norwegian context. Planning Theory and Practice, 12(3), pp. 387-406, 2011.

[13] Alexander, E.R. \& Faludi, A., Planning and plan implementation: Notes on evaluation criteria. Environment and Planning B: Planning and Design, 16(2), pp. 127-140, 1989.

[14] Alexander, E.R., Evaluating planning: What is successful planning and (how) can we measure it? Evaluation for Participation and Sustainability in Planning, eds A. Hull et al., Routledge: London and New York, pp. 32-46, 2011.

[15] Bergström, G. \& Boréus, K. eds., Textens mening och makt. Metodbok i samhällsvetenskaplig text-och diskursanalys, Studentlitteratur: Lund, p. 461, 2005.

[16] Alvesson, M. \& Sköldberg, K., Tolkning och reflektion: Vetenskapsfilosofi och kvalitativ metod, 2nd ed., Studentlitteratur: Lund, 2008.

[17] Loh, C.G. \& Norton, R.K., Planning consultants' influence on local comprehensive plans. Journal of Planning Education and Research, 35(2), pp. 199-208, 2015.

[18] Helberg, N. \& Lundbirk, A.M., Evaluering af 42 lokale handlingsplaner for trafikksikkerhed. Trafikdage på, Aalborg Universitet, Aalborg, p. 7, 2000.

[19] Edvardsen, M., Evaluations of local planning efforts. Evaluation for Participation and Sustainability in Planning, eds A. Hull et al., Routledge: London and New York, pp. 47-66, 2011.

[20] Sorensen, A.D. \& Auster, M.L., Fatal remedies: The sources of ineffectiveness in planning. The Town Planning Review, 60(1), pp. 29-44, 1989.

[21] Elvik, R. et al., The Handbook of Road Safety Measures, 2nd ed., Emerald Group Publishing: UK, 2009. 